\title{
Using LITMUS-MAIN with Norwegian-Russian bilingual children growing up in Norway
}

\section{Yulia Rodina}

UiT The Arctic University of Norway

This paper describes the experience of using the Norwegian and Russian versions of LITMUS-MAIN to elicit narrative data from bilingual Norwegian-Russian children as well as from Norwegian- and Russian-speaking monolinguals (Rodina 2017, 2018). The paper reports on the slight adaptations to the standardized design, procedure and analysis that were done to make the tasks more suitable for this specific population. It highlights the advantages, challenges, and potential associated with the task against a backdrop of the research conducted with Norwegian-Russian bilinguals in Norway.

\section{Introduction}

The Language Impairment Testing in Multilingual Settings - Multilingual Assessment Instrument for Narratives (LITMUS-MAIN, hereafter MAIN, Gagarina et al., 2012, 2015) is an assessment tool which was originally designed for bilingual preschoolers and school-aged children up to the age of ten, but has later been successfully used with older children, adolescents and even adults (see Gagarina, Bohnacker \& Lindgren, 2019). It was revised in 2019 (Gagarina et al., 2019). MAIN is developed specifically for assessing narrative skills in both languages of bilingual speakers. It uses a controlled experimental procedure which enables comparison across the two languages of bilinguals and across different language combinations.

\section{Using MAIN with Norwegian-Russian bilingual preschoolers}

\subsection{Background information}

The Norwegian and Russian versions of the MAIN have been used in two published studies (Rodina 2017, 2018) with simultaneous Norwegian-Russian bilinguals $(N=16, M=4 ; 6)$ as well as with Norwegian $(N=16, M=4 ; 5)$ and Russian monolinguals $(N=16, M=4 ; 5)$. All bilingual participants came from Norwegian-Russian families where the mothers were native 
speakers of Russian and fathers were speakers of Norwegian with no knowledge of Russian. The data collection took place in Oslo, Norway, and Norwegian was the majority language for all participants. Russian was their heritage or home language acquired from birth in the home. Narratives were collected in both languages using the MAIN model story procedure. In the first part of this procedure, either the Cat or the Dog story was presented to the participant who was then asked ten comprehension questions. In the second part, immediately following the first one, the child was asked to narrate a new story, either the Baby Goats or the Baby Birds. Thus, the study tested both narrative comprehension and production but using two different stories. The analysis of the production data included measures of the narrative macrostructure or story structure, as well as the linguistic measures addressing bilinguals' narrative productivity or microstructure at the sentence level.

\subsection{Similarities and differences in tasks and procedure compared to the MAIN manual}

In the studies by Rodina $(2017,2018)$, the tasks and the procedure were not the exactly same as in the MAIN manual (Gagarina et al., 2012, 2019). In what follows, similarities and differences with the MAIN-manual are described.

The Cat and Dog stories were used by the experimenter to establish contact with the participants and to evaluate their comprehension skills. While Norwegian has two written standards, Bokmål and Nynorsk, all Norwegian speakers use their dialects in oral contexts, both formal and informal ones. Thus, it appeared necessary to make some adjustments to the Norwegian story scripts of Cat and Dog compared to the Norwegian MAIN-manual as well as the comprehension questions to make them adhere more to spoken Norwegian and more specifically to the dialect of Norwegian spoken in Oslo. Importantly, the adapted stories had similar lengths compared to the original ones (approximately 170 words) and contained the same words and phrases for the Internal State Terms. The examples in (1) illustrate two adjustments to the Norwegian Cat story. Italics are used to highlight the changes. The wording in the Russian version was also adjusted slightly to have the best possible match between the two language versions. This is shown in the examples in (2).

(1) a. I mellomtiden kom en glad gutt tilbake fra fisketur. [Norwegian MAIN-manual]

'In the meantime, a happy boy came back from a fishing trip.'

a'. Da kom det en glad gutt gående tilbake fra fisketur. [Adapted version]

'Then a happy boy came back from a fishing trip.'

b. Gutten var så forskrekket at ballen falt ut av hånden. [Norwegian MAIN-manual]

b'. Gutten ble så forskrekka at ballen falt rett ut av hånda hans. [Adapted version]

'The boy got upset and the ball fell out of his hand.'

(2) a. Da kom det en glad gutt gående tilbake fra fisketur.

b. В это время мимо проходил мальчик, который возвращался с рыбалки. 
The participants were tested by Russian-speaking monolinguals in Russian and by Norwegianspeaking monolinguals in Norwegian who also spoke the Oslo dialect. This was necessary in order to create a natural language or dialect environment for the children. Using a local dialect for narrative elicitation in Norwegian may be especially important, as Norwegian-speaking children are known to adjust their speech during role-play, where they show a tendency to switch to the Eastern Norwegian dialect (e.g. Eliassen 1998, Kleeman 2015). Therefore, using a local dialect to elicit narrative production ensures the best outcome, especially if one is interested in studying the microstructure and children's language proficiency.

In order to keep the narratives that the children heard in the model story identical for all participants, the Cat and Dog stories were audio-recorded. The experimenter played one of the stories for a child while showing the accompanying series of pictures and afterwards asked the ten comprehension questions. This procedure was very successful and had practical advantages given that the data collection was conducted by several research assistants in each of the languages. Afterwards, the participant was asked to narrate a new story, Baby Goats or Baby Birds. As described in the MAIN manual, each story was copied three times and placed in three differently coloured envelopes. The participant was asked to choose one of the envelopes and tell the story without showing it to the experimenter.

The procedure with model story and telling took approximately 15 minutes per participant, yet the data collection was rather time-consuming. There is virtually no preschool immersion education in Norway and bilinguals usually attend different Norwegian-speaking kindergartens. Only some bilinguals are enrolled in Russian language centers on weekends where the testing took place.

\subsection{Experience with data analysis and results: changes and reflections}

The bilingual sample size reported in Rodina (2017) is relatively small, yet it represents only a selection of participants. As many as 15 bilinguals were not included in the study, since some children failed to tell a story in either Norwegian or Russian. Some other children, mainly 4year-olds, produced very short narratives consisting of only a few words. A high drop-out rate in narrative studies is not unexpected especially when the target group are bilingual pre-school children. There were drop-outs in both groups of monolinguals as well.

Reliability is an important issue in the narrative data analysis and it was absolutely necessary to have two raters as well as an additional rater for resolving some unclear/uncertain cases and conflicting views.

The scoring procedure and analysis of the comprehension data elicited with the Cat and Dog stories was rather straightforward with the exception of question 10. The results reported in Rodina (2017) suggest that question 10 (Will the boy be friends with the cat/dog?) is not felicitous, as both bilingual and monolingual children favored a positive answer to this question which is considered to be erroneous in the MAIN manual. While some of the children could not explain their choice, others said that the protagonists would still be friends, since animals are man's friends. They thus relied on their common sense or world knowledge. Given this, one 
should treat the results for question 10 with caution and consider using a nine-point scale for the Cat and Dog stories.

The narrative production data elicited with the Baby Goats and Baby Birds stories was used to measure the story structure. Rodina (2017) used the standard 17-point scale from the MAIN manual, i.e. the story structure score. The scoring procedure and analysis of the production data required some decision-making. First, there were cases when children's production did not match the alternatives suggested in the manual. For example, to introduce new protagonists in the story, such as fox and bird in Baby Goats and cat and dog in Baby Birds, the children typically used the sentences in (3) and (4) in Norwegian and Russian respectively. Given a considerable number of such phrases in the data, it was decided to categorize them as 'IST as initiating event' (A7 and A12 in the manual). It should be noted that this deviates considerably from how this component is described and coded for according to the MAINmanual (Gagarina et al., 2019), as such cases do not contain any internal state terms (ISTs). Awarding points for cases such as in (3) and (4) leads to higher story structure scores, compared to when the original MAIN-scoring is kept.

(3) Og så kom det en rev.

'And so a fox came.'

(4) A potom prišla sobaka.

'And then a dog came.'

Furthermore, during coding it became clear that one sentence can include several macrostructure elements and that the elements may not appear in the order outlined for each of the three story episodes, which is IST as initiating event - Goal - Attempt - Outcome - IST as reaction. The example in (4) shows that the Attempt ('wants to eat the chicks') precedes the Goal ('the cat climbed up the tree'), while the reverse order would be more natural. This observation holds for the narrative production overall: Despite the fact that the story episodes are presented in a serial order in the pictures, preschool children tend to go back and forth between the episodes allowing, for example, Attempts to precede Goals. This is not a change in scoring compared to the MAIN-manual, but rather a reflection based on the experiences of using MAIN.

(4) koška zalezla na gnezdo i hočet sjest' cyplyatki

'The cat climbed up the tree and wants to eat the chicks.'

\subsection{Summary of the results for microstructural measures}

In addition to the story structure score, Rodina (2017) used six linguistic measures to investigate the bilinguals' narrative productivity, a part of the microstructure: the number of C-units (CU), ${ }^{1}$ the total number of word tokens (TNW), the number of different word tokens (NDW), mean

${ }^{1}$ The C- (communication unit) or T-unit (minimal terminable unit) is usually described as a main clause and its subordinate clauses. 
length of CU in word tokens (MLU), the total number of verb tokens (TNV) and the total number of noun tokens (TNN). In Rodina (2017), the link between these microstructural measures and the story structure score was investigated. It was found that the narrative productivity data of 16 Norwegian-Russian bilinguals revealed that only one linguistic measure showed a significant relation to the story structure score, namely MLU, which correlated positively with the story structure score in Russian. None of the six linguistic measures correlated significantly with the story structure score in Norwegian. Thus, bilinguals' story structure in both languages appears to be independent of the narrative productivity. However, it is yet unclear whether these results are generalizable to a larger bilingual population.

It should be highlighted that MAIN appears to be highly suitable for measuring microstructure in bilinguals' narratives, for example providing information about the amount of linguistic material produced, lexical diversity or syntactic complexity. Recent studies investigating the acquisition of grammatical gender in Russian heritage speaking children have used the MAIN narratives as a language proficiency measure (Mitrofanova, Rodina, Urek \& Westergaard, 2018; Rodina, Kupisch, Meir, Mitrofanova, Urek \& Westergaard, 2020). Specifically, the number of different words in a Russian narrative was found to correlate significantly with the bilinguals' performance on a grammatical gender task. This suggests that a lexical diversity measure, such as the number of different words produced in the MAIN narratives, can be a significant explanatory variable and can be used to assess bilingual language proficiency. MAIN can thus be used as an additional measure in studies investigating bilingual language development.

\section{Summary and conclusions}

My experience with the MAIN tasks, as presented in the present paper, allows me to conclude that MAIN is a useful tool for studying the narrative abilities of bilinguals growing up in Norway with Russian as their heritage language. It offers a rich source of data for analysis, has a simple and structured design, and a user-friendly scoring system.

\section{$4 \quad$ References}

Eliassen, C. (1998). Rollelekspråk. [The language of the role play.]. MA dissertation, Trondheim University of Science and Technology.

Gagarina, N., Bohnacker, U., \& Lindgren, J. (2019). Macrostructural organization of adults' oral narrative texts. ZAS Papers in Linguistics, 62, 190-208.

Gagarina, N., Klop, D., Kunnari, S., Tantele, K., Välimaa, T., Balčiūnienė, I., Bohnacker, U. \& Walters, J. (2012). MAIN: Multilingual Assessment Instrument for Narratives. ZAS Papers in Linguistics, 56.

Gagarina, N., Klop, D., Kunnari, S., Tantele, K., Välimaa, T., Balčiūnienė, I., Bohnacker, U., \& Walters, J. (2015). Assessment of Narrative Abilities in Bilingual Children. In S. Armon-Lotem, J. de Jong, \& N. Meir (Eds.), 
Assessing multilingual children: Disentangling bilingualism from language impairment (pp. 243-269). Bristol: Multilingual Matters.

Gagarina, N., Klop, D., Kunnari, S., Tantele, K., Välimaa, T., Bohnacker, U., \& Walters, J. (2019). MAIN: Multilingual Assessment Instrument for Narratives - Revised. ZAS Papers in Linguistics, 63, 1-36.

Kleeman, C. B. (2015). Lek på to språk - en studie av kodeveksling og språkalternering i tospråklig rollelek på nordsamisk og norsk i en samisk barnehage. [Playing in two languages: A study of code-switching and language use during the role play in a bilingual Norwegian-Sami kindergarten]. PhD dissertation, UiT the Arctic University of Norway.

Mitrofanova, N., Rodina, Y., Urek, O., \& Westergaard, M. (2018). Bilinguals' sensitivity to grammatical gender cues in Russian: The role of cumulative input, proficiency, and dominance. Frontiers in Psychology, DOI: https://doi.org/10.3389/fpsyg.2018.01894.

Rodina, Y. (2018). Kartlegging av narrative ferdigheter hos simultant tospråklige: Evaluering av LITMUS-MAIN verktøy. [Assessment of the narrative abilities of the simultaneous bilinguals: Evaluation of the LITMUSMAIN task] Norsk tidskrift for logopedi, 64(2), 5-17.

Rodina, Y. (2017). Narrative skill acquisition in preschool bilingual Norwegian-Russian children. International Journal of Bilingualism, 21(5), 617-635.

Rodina, Y., Kupisch, T., Meir, N., Mitrofanova, N., Urek, O., \& Westergaard, M. (2020). Internal and external factors in heritage language acquisition: Evidence from Heritage Russian in Israel, Germany, Norway, Latvia and the UK. Frontiers in Education. DOI: https://doi.org/10.3389/feduc.2020.00020. 